\title{
Kültür Endüstrisi Bağlamında Reklam ve Din İlişkisi: Göstergebilimsel Bir Çözümleme
}

\author{
Relationship between Advertisement and Religion in the Context of the Culture \\ Industry: A Semiotic Analysis
}

\section{Feyza Nur Kaleci ${ }^{*}$ (1)}

Öz

Kültür endüstrisi, kâr güdüsüyle hareket ederek yapay, ticarileşmiş ve standartlaşmış bir kültür üretmektedir. Kültür endüstrisinin en önemli anlatım ve aktarım araçlarından birini oluşturan reklamlar, endüstrinin değişim ve ihtiyacına göre ifade biçimlerini farklılaştırarak endüstri pratiğinin yayılmasına hizmet etmektedir. Reklamlar ayrıca toplumun kültürel kodlarını, dini değer ve inançlarını çağrıştran sembolleri, endüstrinin işleyişine uygun bir şekilde dönüştürüp ticarileştirmektedir. Bu çalışma, reklam ve din ilişkisini kültür endüstrisi çerçevesinde ele almayı amaçlamaktadır. Çalışmada Roland Barthes'in göstergebilimsel çözümleme yöntemi kullanılmakta; örnekleme yöntemi doğrultusunda seçilen reklam göstergelerinde dini sembollerin nasıl konumlandığı, popüler kültür formları ile nasıl ilişkilendirildiği ve reklam göstergelerinin sunulanın dışında başka nelere işaret edebileceği sorgulanmaktadır. Göstergebilimsel çözümleme sonucunda elde edilen verilere göre reklam göstergelerinde dini semboller, alınıp satılabilen bir tüketim nesnesine ya da estetik bir biçim kazandırılarak tüketiciyi satın alma faaliyetine yönelten bir arzu ve güdümleme nesnesine dönüşmekte; kimi zaman da reklam retoriği içinde kullanılan bir gimmick olarak işlev görmekte ya da gimmicklerle eklektik bir biçimde işlevselleştirilmektedir. Reklam göstergeleri, bir taraftan dini sembolleri kullanarak bireyleri tüketime yönlendirirken, diğer taraftan bireylerin dini sembollere yönelik zihin dünyalarındaki anlamsal yapıların dönüşmesine aracılık etmektedir.

\section{Anahtar Kelimeler}

Popüler Kültür, Kültür Endüstrisi, Reklam, Din, Göstergebilim

\begin{abstract}
The culture industry produces an artificial, commercialized and standardized culture, motivated by profit. Advertisements, which constitute one of the most important expressions and transfer tools of the culture industry, spread the industry practices by differentiating the forms of expression according to the changes and needs of the industry. Advertisements also transform and commercialize the symbols that evoke the cultural codes, religious values and beliefs of the society in accordance with the industry functions. This study aimed to examine the relationship between advertisement and religion within the framework of the culture industry. The semiotic analysis method of Roland Barthes was used in the study. The study questions how religious symbols are positioned in the advertising indicators selected in line with the sampling method, how they relate to popular culture forms, and what other factors advertising indicators can be used to identify. According to the data obtained from the semiotic analysis, religious symbols in advertising indicators turn into objects of consumption that can be bought and sold or objects of desire and motivation that direct the consumer to a purchasing activity by adding an aesthetic shape. Religious symbols sometimes function as a gimmick used in advertising rhetoric or are functionalized eclectically with gimmicks. Advertising indicators, while directing individuals to consumption by using religious symbols, mediate the transformation of semantic structures for religious symbols in the minds of individuals.
\end{abstract}

\section{Keywords}

Popular Culture, Culture Industry, Advertisement, Religion, Semiology

* Sorumlu Yazar: Feyza Nur Kaleci (Arş. Gör.), İstanbul Üniversitesi, illahiyat Fakültesi, Felsefe ve Din Bilimleri Bölümü, İstanbul, Türkiye. E-mail: feyzakaleci@istanbul.edu.tr ORCID: 0000-0001-5884-4968

Atf: Kaleci, Feyza Nur, "Kültür Endüstrisi Bağlamında Reklam ve Din İlişkisi: Göstergebilimsel Bir Çözümleme." darulfunun ilahiyat 32, 1 (2021): 89-116. https://doi.org/10.26650/di.2021.32.1.804142 


\section{Extended Summary}

Approaches to popular culture are basically shaped by whether individuals play an active role in the formation of popular culture. Along with approaches that consider popular culture as a culture that is liked and consumed by most people in the society and that emphasizes the conscious choice of individuals there are also approaches that consider popular culture as a manipulative tool of domination and that emphasize making individuals passive. This study, which deals with the relationship between advertisement and religion, was based on Frankfurt School's "culture industry" analysis, one of the representatives of the second approach. The Frankfurt School evaluates popular culture as an artificial culture that is produced and commercialized with a profit motive and spreads to the public. Theodor W. Adorno and Max Horkheimer, who are among the thinkers of the Frankfurt School, argue that culture has become an industry by commercializing with the concept of culture industry, which they developed to criticize popular culture, and creates a collective unconsciousness by making individuals passive with consumerism. According to thinkers, cultural contents are produced and presented to the market as standard consumption objects by the industry. Standardizing cultural contents and putting them on the market cause individuals to erode and standardize their ability to think critically and dialectically. By instilling a false consciousness, the culture industry integrates individuals with the system and creates a conformist consumer society. Advertisements play an important role in the formation of consciousness in accordance with the industry functions. Advertisements, which constitute one of the most important tools of expression and transmission of the cultural industry, lead individuals to consumption and strengthen the dominance of the system. Advertisements transform and commercialize the values and symbols belonging to all areas of the society in accordance with the industry functions. Advertisements also place religious symbols into popular forms, turning them into objects of consumption that are reproduced and consumed with new content. This study aimed to examine the relationship between advertisement and religion within the framework of culture industry. The study questions how religious symbols are positioned in the advertising indicators selected in line with the sampling method, how they relate to popular culture forms, and what other factors advertising indicators can be used to identify.

The purposive sampling method was used in the study. The study sample consisted of 10 advertising indicators that are compatible with the purpose of the study and allow the basic problems to be addressed from different aspects. The sample was limited to 10 advertising indicators, considering the saturation of the data for the purpose of the study and the state of self-repetition. For diversity of the study sample, no year or brand was preferred in the selection of advertising indicators. In this respect, the arguments obtained from the study are limited to the advertising indicators selected in line with the sampling method. The advertising indicators were analyzed using a semiotic analysis method, for which the approach developed by Roland Barthes is preferred. 
According to the data obtained from the semiotic analysis, religious symbols in advertising indicators turn into objects of consumption that can be bought and sold or objects of desire and motivation that directs the consumer to a purchasing activity by adding an aesthetic shape. Religious symbols sometimes function as a gimmick used in advertising rhetoric or are functionalized eclectically with gimmicks. Advertising indicators, while directing individuals to consumption by using religious symbols, mediate the transformation of semantic structures for religious symbols in the minds of individuals. 


\section{Giriş}

Popüler kültüre yönelik yaklaşımlar temelde, popüler kültür oluşumunda bireylere aktif bir rol yüklenip yüklenmemesi üzerinden şekillenmektedir. Popüler kültürü, toplumun çoğunluğu tarafından beğenilen ve tüketilen bir kültür olarak değerlendirip bireylerin bilinçli tercihine vurgu yapan ve popüler kültürde bir direniş potansiyeli saptayan yaklaşımlar olmakla birlikte; popüler kültürü, manipülatif bir tahakküm aracı olarak değerlendirip bireyleri pasifleştirdiğine vurgu yapan yaklaşımlar da bulunmaktadır. ${ }^{1}$ Reklam ve din ilişkisini ele alan bu çalışma, ikinci yaklaşımın temsilcilerinden Frankfurt Okulu'nun "kültür endüstrisi" çözümlemesi üzerinden hareket etmektedir. Frankfurt Okulu, popüler kültürü kâr güdüsü ile üretilip ticarileşen ve halka doğru yayılan yapay bir kültür olarak değerlendirmektedir. Okul düşünürlerinden Theodor W. Adorno ve Max Horkheımer, popüler kültürü eleştirmeye yönelik geliştirdikleri kültür endüstrisi kavramı ile kültürün ticarileşerek bir endüstri haline geldiğini ve bireyleri tüketicilikle pasifize ederek kolektif bir bilinçsizlik hali oluşturduğunu ileri sürmektedir. Düşünürlere göre endüstri tarafindan kültürel içerikler, standart şekilde bir tüketim nesnesi olarak üretilmekte ve piyasaya sunulmaktadır. ${ }^{3}$ Kültürel içeriklerin standartlaştırılarak piyasaya sunulması, bireylerin eleştirel ve diyalektik olarak düşünme yeteneklerini aşındırıp standartlaşmalarına yol açmaktadır. Kültür endüstrisi, yanlış bir bilinç aş1layarak bireyleri sistemle bütünleştirmekte ve konformist bir tüketim toplumu oluşturmaktadır. Endüstrinin işleyişine uygun bilincin oluşmasında ise reklamlar önemli bir rol oynamaktadır. Kültür endüstrisinin en önemli anlatım ve aktarım araçlarından birini oluşturan reklamlar, bireyleri tüketime yönlendirmekte ve sistemin egemenliğinin pekişmesine hizmet etmektedir. ${ }^{4}$ Reklamlar ayrıca toplumsalın her alanına ait değer ve sembolleri endüstrinin işleyişine uygun bir şekilde dönüştürüp ticarileştirmektedir. Dini sembolleri de rekabet ve pazar mantığının işlediği döngüde popüler formların içine yerleştirmekte; yeni içeriklerle tekrar üretilip tüketilir hale gelen tüketim nesnelerine dönüştürmektedir. Bu çalışma, reklam ve din ilişkisini, kültür endüstrisi çerçevesinde ele almayı amaçlamaktadır. Çalışmada reklam göstergelerinde dini sembollerin nasıl konumlandığı, popüler kültür formları ile nasıl ilişkilendirildiği ve reklam göstergelerinin sunulanın dışında başka nelere işaret edebileceği sorgulanmaktadır.

1 Karşılaştırmalı bir analiz için bkz. Douglas Kellner, "Kültürel Marksizm ve Kültürel Çalışmalar”, çev. Fatih Tezcan, ETHOS: Felsefe ve Toplumsal Bilimlerde Diyaloglar 9(2) (2016).

2 Theodor W. Adorno - Max Horkheımer, Aydınlanmanin Diyalektiği Felsefi Fragmanlar, çev. Nihat Ülner - Elif Öztarhan Karadoğan (İstanbul: Kabalcı Yayıncılık, 2014), 162.

3 Theodor W. Adorno, “Kültür Endüstrisini Yeniden Düşünürken”, çev. Bülent O. Doğan, Cogito Adorno: Kitle, Melankoli ve Felsefe 36 (2003), İstanbul: Yapı Kredi Yayınları, 78.

4 Adorno - Horkheımer, Aydınlanmanın Diyalektiği, 215. 
Çalışmada amaçlı örnekleme yöntemi (purposive sampling) $)^{5}$ kullanılmaktadır. Çalışmanın örneklemi, çalışmanın amacı ile uygunluk gösteren ve temel problemlerin farklı yönleri ile ele alınmasına olanak sağlayan on reklam göstergesinden oluşmaktadır. Örneklem, çalışmanın amacına yönelik verilerin doygunluğu ve kendini tekrar etme durumu göz önünde bulundurularak on reklam göstergesi ile sınırlandırılmaktadır. Örneklemin çeşitlilik arz etmesi amacıyla reklam göstergelerinin seçiminde herhangi bir yıl ya da marka tercih edilmemektedir. $\mathrm{Bu}$ bakımdan çalışmadan elde edilen argümanlar, örnekleme yöntemi doğrultusunda seçilen reklam göstergeleri ile sinırlıdır.

Çalışmada reklam göstergeleri, göstergebilimsel çözümleme yöntemi kullanılarak analiz edilmektedir. Göstergebilimsel çözümleme yöntemi olarak Roland Barthes'in geliştirmiş olduğu yaklaşım tercih edilmektedir. Göstergebilimin temsilcilerinden Ferdinand de Saussure, Charles Sanders Peirce ve Roland Barthes'in yaklaşımları birbirinden farklılık arz etmektedir. Saussure temelde, yapısal kökenli bir göstergebilim anlayışını savunarak göstergelerin toplumsal işlevini; Peirce, mantıksal kökenli bir göstergebilim anlayışını savunarak göstergelerin mantıksal işlevini vurgulamaktadır. ${ }^{6}$ Barthes ise Saussure geleneğinin temsilcilerinden biri olmakla birlikte, Saussure'ün göstergebilimi dilbilimin üstünde görmesi durumunu değiştirerek göstergebilimi dilbilimin alt bölümü olarak görmekte ve göstergebilimin konusunu her türlü göstergeler dizgesi olarak belirlemektedir. ${ }^{7}$ Böylece Saussure'ün göstergeye yüklediği anlamın sınırlarını genişletmektedir. Bununla birlikte Barthes, göstergelere eleştirel yaklaşmakta; göstergebilimin toplumsal eleştiriyi harekete geçirerek bir toplumun nasıl yapay oluşumlar ürettiğini ve sonradan bunları doğal oluşumlarmış gibi nasıl tükettiğini anlama ve açığa çıkarma işlevi gördüğünü belirtmektedir. ${ }^{8}$ Çağdaş Söylenler adlı eserinde reklamların, filmlerin kitle kültürünün oluşmasına nasıl aracılık ettiklerini ve modern toplumlarda hangi ideolojik amaçlara hizmet ettiklerini çözümlemektedir. ${ }^{9}$ Dolayısıyla Barthes'in göstergebilimsel yaklaşımı, toplumsalı eleştirel bir okumaya tabi tutmakta ve sosyolojik çözümlemelere daha yakın görülmektedir. ${ }^{10}$ Bu bakımdan çalışmada

5 Amaçlı örnekleme yöntemi (purposive sampling), çalışmanın amacına uygun nitelikte olduğu düşünülen örneklerin seçildiği örnekleme yöntemidir.

6 Ufuk Bircan, "Roland Barthes ve Göstergebilim”, Sosyal Bilimler Araştırma Dergisi, 26 (2015): $18-19$.

7 Roland Barthes, Göstergebilim Illkeleri, çev. Berke Vardar - Mehmet Rifat (Ankara: Kültür Bakanlığı Yayınları, 1979), XXII.

8 Roland Barthes, Bir Deneme Bir Ders: Eiffel Kulesi ve Açılış Dersi, çev. Mehmet Rifat - Sema Rifat (İstanbul: Yapı Kredi Yayınları, 2015), 57.

9 Roland Barthes, Çağdaş Söylenler, çev.Tahsin Yücel (İstanbul: Metis Yayınları, 2014).

10 Birsen Banu Okutan, Din Sosyolojisi ve Göstergebilim (İstanbul: Rağbet Yayınları, 2018), 81. 
göstergebilimsel çözümleme yöntemi olarak Barthes' in geliştirmiş olduğu yaklaşım tercih edilmektedir. Barthes, göstergebilimin temellerini dil-söz, gösteren-gösterilen, dizim-dizge ve düz anlam-yan anlam şeklinde düzlemsel yapılandırmalar yani ikili sınıflandırmalar ile kurmaktadır. ${ }^{11} \mathrm{Bu}$ düzlemsel yapılandırmaları, göstergebilimin başlıca çözümleme araçları olarak kullanmaktadır. Çalışmada seçilen reklam göstergeleri ise gösteren-gösterilen düzlemleri üzerinden çözümlenmektedir.

\section{Kuramsal Çerçeve: Frankfurt Okulu ve Kültür Endüstrisi}

Frankfurt Okulu düşünürleri, modern dünyada bireysel ve toplumsal özgürlüğün gerçekleşmesine katkıda bulunmaya yönelik bir eleştirel toplum teorisi geliştirmiştir. Frankfurt Okulu düşünürleri tarafından geliştirilen eleştirel teori, Karl Marx'ın "yabancılaşma", Emile Durkheim'ın "anomi” ve Max Weber'in "demir kafes" analizleri ile ilişkili olarak modern toplumlardaki egemenlik biçimlerinin eleştirel bir analizini içermektedir. ${ }^{12}$ Okul düşünürlerine göre modern toplumlar, görünenin aksine özgür ve rasyonel değil; baskı altında ve irrasyoneldir. Modern toplumlarda araçsal rasyonelliğin yükselişi, özgürlüğü ve rasyonelliği artırmamıştır. Aksine araçsal rasyonelliğin ürettiği bask1, bireylerin eleştirel ve diyalektik olarak düşünme yeteneklerini, rasyonel seçme ve karar verme gibi temel özgürlüklerini aşındırmıştır. ${ }^{13}$ "Araçsal rasyonelliğin irrasyonelliği" ${ }^{14}$ olarak nitelendirilen bu durum karşısında bireyler, özgürlüğünü ve özneliğini kaybetmeye başlayarak kendilerine yabancılaşmış; benzer hale gelerek tek tipleşmiştir. Bireylerin kendilerine yabancılaşması ve "tek boyutlu" hale gelmesi, teknoloji ve bilimin üretim ilişkilerine eklemlenmesi, kitle iletişim araçlarının yaygınlaşması ve kültürün endüstri haline gelerek konformist bir tüketim toplumu oluşturması ile pekişmiştir. ${ }^{15}$ Okul düşünürlerinden Theodor W. Adorno ve Max Horkheimer, modern toplumlarda bireylerin özellikle kültürel olarak baskı altında tutulmaları üzerinde odaklanmış; Aydınlanmanın Diyalektiği adlı eserde endüstrileşerek konformist bir tüketim toplumu oluşturan kültürü eleştirmeye yönelik "kültür endüstrisi”" ${ }^{16}$ kavramını geliştirmiştir.

11 Barthes, Göstergebilim Ilkeleri.

12 Martin Slattery, Sosyolojide Temel Fikirler, çev. Ümit Tatlıcan - Gülhan Demiriz (İstanbul: Sentez Yayıncilik, 2015), 204.

13 George Ritzer, Modern Sosyoloji Kuramları, çev. Himmet Hülür (Ankara: De Ki Basım Yayım, 2012), 144.

14 George Ritzer, Toplumun McDonaldlaştırılması Çă̆daş Toplum Yaşamının Değişen Karakteri Üzerine Bir İnceleme, çev. Şen Süer Kaya (İstanbul: Ayrıntı Yayınları, 2011), 50.

15 Herbert Marcuse, Tek Boyutlu İnsan İleri İsleyim Toplumunun İdeolojisi Üzerine İncelemeler, çev. Aziz Yardımlı (İstanbul: İdea Yayınları, 1990).

16 Adorno - Horkheımer, Aydınlanmanın Diyalektiği, 162. 
Adorno ve Horkheımer, popüler kültür ya da kitle kültürü kavramlarını kullanmak yerine kültür endüstrisi kavramını geliştirerek halk kültürü ile kitle kültürü arasındaki karşıtlığa vurgu yapmakta; popüler kültürün halkın içinden kendiliğinden yükselen gerçek bir kültür, halkın kendi ilgi alanlarının özerk bir ifadesi ve halk sanatının günümüzdeki biçimi olarak anlaşılması ihtimalini ortadan kaldırmaktadır. ${ }^{17}$ Düşünürlere göre halk, gerçekte kültürün üreticisi konumunda iken, kültür endüstrisi ile birlikte tüketici konumundadır. Tüketici ise kültür endüstrisinin halkı ikna etmeye çalıştığı gibi özne değil; endüstrinin devamlılığını sağlayan birer nesne konumundadır. ${ }^{18}$ Kültür endüstrisinin ürettiği kültür de halkın içinden kendiliğinden yükselen gerçek bir kültür değil; halka doğru yayılan, imal edilmiş yapay bir kültürdür. Kültür endüstrisi, kâr güdüsüyle hareket ederek ${ }^{19}$ yapay, ticarileşmiş ve standartlaşmış bir kültür üretmektedir.

Adorno ve Horkheımer, endüstri kavramıyla doğrudan üretim sürecine değil; kültürel ürünlerin standartlaştırılmasına ve rasyonelleşmiş dağıtım teknikleriyle piyasaya sunulmasına işaret etmektedir. ${ }^{20}$ Endüstri tarafından kültürel içerikler standart şekilde meta ${ }^{21}$ biçiminde üretilmekte ve rasyonelleşmiş dağıtım teknikleriyle tüketim âlemine yerleştirilmektedir. Kültürel içerikler, ticarileşerek seri üretimle sermaye sisteminin ayrılmaz bir parçası haline gelmekte; piyasa mantığının işlediği döngü içinde deformasyona uğrayarak gerçek değerini yitirmektedir.

Adorno ve Horkheımer'ın kültür endüstrisine yönelik temel eleştirileri, endüstri tarafindan kültürel içeriklerin standartlaştırılması ve rasyonelleşmiş dağıtım teknikleriyle piyasaya sunulmasının, bireylerin eleştirel ve diyalektik olarak düşünme yeteneklerini aşındırıp standartlaşmalarına yol açtığıdır. Kültür endüstrisi, bireylere anlaşılması ve tüketilmesinde bilinçsel bir çabanın gerekli olmadığ 1 , oldukça basitleştirilmiş standart ürünler sunmaktadır. Endüstri, standardizasyonun tamamlayıcısı olarak kullandığı "sözde bireysellik tekniğì" 22 ile

17 Theodor W. Adorno, Kültür Endüstrisi Kültür Yönetimi, çev. Nihat Ülner - Mustafa Tüzel - Elçin Gen (İstanbul: İletişim Yayınları, 2011), 109.

18 Adorno, "Kültür Endüstrisini Yeniden Düşünürken”, 76.

19 Adorno, "Kültür Endüstrisini Yeniden Düşünürken”, 77.

20 Adorno, "Kültür Endüstrisini Yeniden Düşünürken”, 78.

21 Meta, tüketime uygun biçimde hazırlanmış, kayıt altına alınmış, endüstriyel üretime uyarlanmış, satılabilir ve ikame edilebilir ürün anlamına gelmektedir. Adorno - Horkheımer, Aydınlanmanın Diyalektiği, 211. Metalaşma ise daha önce ekonominin dışında olup bir market değeri olmayan servis, ürün veya ilişkilerin ekonominin içine alınmasıyla birlikte bir market (değiş-tokuş) değeri kazanmasını ifade etmektedir. İsmail Demirezen, Tüketim Toplumu ve Din (İstanbul: Dem Yayınları, 2019), 40.

22 Phıl Slater, Frankfurt Okulu, çev. Ahmet Özden (İstanbul: Kabalcı Yayınevi, 1998), 234. 
standart ürünleri farklı şekil, fiyat ve markalarla piyasaya sürmektedir. Bu sayede ürünleri bireyselmiş gibi göstererek ${ }^{23}$ mümkün olduğunca fazla sayıda tüketici kitlesine hitap edebilmektedir. Sözde bireysellik tekniği ile ayrıca özgür seçim ve tüketici ihtiyaçlarının endüstri üretiminde rol oynadığına işaret edilmektedir. Endüstri, ürettiği standart ürünlerin tüketicilerin ihtiyaçlarından kaynaklandığını öne sürmektedir. ${ }^{24}$ Tüketicilere de bu standart ürünleri satın alarak ihtiyaçlarını karşılayabileceklerini vaat etmektedir. Gerçekte ise endüstri, herkes için uygun bir şeyler öngörüp ${ }^{25}$ ihtiyaçlar üretmekte; "bu ihtiyaçları, önceden bireylerin hep bir tüketici ve sadece kültür endüstrisinin bir nesnesi olarak yaşamasını sağlayacak biçimde düzenlemektedir." ${ }^{26}$ Endüstri, ürettiği tüketici ihtiyaçlarını öngörülen standart ürünlerle karşılamaya çalışarak bireylerde aldatıcı bir memnuniyet duygusu ve ikame bir doyum oluşturmaktadır. ${ }^{27}$ Bireylerin kendilerine sunulan ürünlerin niceliğiyle birlikte güdülebilirlikleri de artmaktadır. ${ }^{28}$

Endüstride özgür seçim ise standardizasyonun dayanak alındığı bir seçimdir. ${ }^{29}$ Bireylerin geniş bir seçim özgürlüğü var gibi görünmektedir. Üretici güçlerin gelişmesiyle birlikte bireylerin özgürlügü de artmıştır. ${ }^{30}$ Ancak bireylerin özgürlüğü gibi görünen özgürlük, gerçekte sahte ihtiyaçlar üreten endüstrinin kendi özgürlügüüdür. Marcuse’a göre sistem, aldatıcı özgürlükleri sürdürmek için ihtiyaçları zorunlu kılmaktadır. Bireylerin de kendilerine dayatılan ihtiyaçları kendilerine sunulan standart ürünlerden seçim yaparak karşılamaya çalışmaları ve böylece özgürleştiklerine inanmaları sözde bir özgürlüğe işaret etmektedir:

"Bireye açık olan seçmelerin erimi, birey özgürlügünün derecesini saptamada belirleyici bir etmen değildir: Yalnızca birey tarafından neyin seçilebileceğini ve neyin seçilmiş olduğunu göstermeye yaramaktadır. Efendileri özgürce seçme, efendileri ya da köleleri ortadan kaldırmamaktadır. Geniş bir mallar ve hizmetler türlülüğü içerisinde özgür seçim, özgürlüğü imlemez. Yukarıdan dayatılan ihtiyaçların bireyler tarafından yeniden üretimi özerkliği kurmaz; yalnızca denetimlerin etkerliğine tanıklı etmektedir."’31

23 Adorno, Kültür Endüstrisi Kültür Yönetimi, 112.

24 Adorno - Horkheımer, Aydinlanmanın Diyalektiği, 163.

25 Adorno - Horkheımer, Aydınlanmanın Diyalektiği, 166.

26 Adorno - Horkheimer, Aydınlanmanın Diyalektiği, 189.

27 Adorno, Kültür Endüstrisi Kültür Yönetimi, 119.

28 Adorno - Horkheimer, Aydınlanmanın Diyalektiği, 14.

29 Slater, Frankfurt Okulu, 234.

30 Max Horkheımer, Akıl Tutulması, çev. Orhan Koçak (İstanbul: Metis Yayınları, 2013), 123.

31 Marcuse, Tek Boyutlu Insan, 7. 
Sonuçta sınırları belirlenmiş, sözde bireysel ve özgür bir sistemin içerisinde gerçekte olan, kültür endüstrisinin yanlış bir bilinç aşllayarak bireyleri sistemle bütünleştirip baskı altında tuttuğudur. Endüstri, kendi ihtiyacı olan kültürü üreterek kendi işleyişine uygun bir şekilde bireylere empoze etmekte; kültür de ideolojik bir egemenlik biçimi olarak işlev görmektedir. Endüstri pratiğinin tescilli ve denenmiş olarak bilince yerleştirilmesi ${ }^{32}$ ve sürekli tekrarlanarak ideal olanmış gibi bireylere sunulması, ${ }^{33}$ araçsal rasyonelliği artırmaktadır. Böylece bireylerin, eleştirel ve diyalektik olarak düşünme yetenekleri aşınmakta; tek boyutlu bir düşünce ve davranış kalıbı ortaya çıkmaktadır. Bireyler kendilerine sunulan ihtiyaçlar ve standart ürünler doğrultusunda "koşullandırılmış alıcılar" ${ }^{34}$ olarak endüstri pratiğini sorgulamadan, analiz etmeden ve diyalektik olmayan bir biçimde kabul etmektedir. Yaşamlarını sistemin var olma koşullarına uyarak ${ }^{35}$ ve tüketim mekanizmasının isteklerini yerine getirerek sürdürmektedir. Uyum, öznel davranışların ölçütü ${ }^{36}$ haline gelince bireyler, özneliğini kaybetmeye başlayarak kendilerine yabancılaşmakta ve konformizme şartlandırılarak standartlaşmaktadır.

\section{Din ve Bir Kültür Endüstrisi Aracı Olarak Reklamlar}

Kültür endüstrisinde standartlaştırılmış üretimin devamlılı̆̆ı, standartlaştırılmış bir bilinç yönetimiyle sağlanmaktadır. Endüstrinin işleyiş̧ine uygun bilincin oluşmasında ise reklamlar önemli bir rol oynamaktadır. Reklamlar, kültür endüstrisi ile hem teknik hem de ekonomik bakımdan bütünleşerek ${ }^{37}$ sistemin egemenliğinin pekişmesinde önemli işlevler üstlenmekte; endüstrinin değişim ve ihtiyacına göre ifade biçimlerini farklılaştırarak endüstri pratiğinin yayılmasına hizmet etmektedir. Bu bakımdan Adorno ve Horkheımer'a göre reklamlar, kültür endüstrisinin “yaşam iksiri” ${ }^{38}$ olarak görülmektedir.

Reklamlar tüketilecek popüler ürünü endüstri için işlevsel şekilde satın alma eylemine hazırlamakta ve aktarılmaya hazır hale getirmektedir. Arzu oluşturma stratejileriyle ${ }^{39}$ bireylerde satın alma güdüsünü canlı tutmakta ve onları tüketime

32 Theodor W. Adorno, Edebiyat Yazıları, çev. Sabir Yücesoy - Orhan Koçak (İstanbul: Metis Yayınları, 2004), 167.

33 Adorno - Horkheımer, Aydınlanmanın Diyalektiği, 197.

34 Marcuse, Tek Boyutlu Insan, 7.

35 Horkheimer, Akıl Tutulması, 121.

36 Horkheimer, Akll Tutulması, 122.

37 Adorno - Horkheımer, Aydınlanmanın Diyalektiği, 217.

38 Adorno - Horkheımer, Aydınlanmanın Diyalektiği, 215.

39 Reklamlarda arzu oluşturma stratejilerine yönelik ayrıntılı bilgi için bkz. Armand Mattelart, Reklamcılık, çev. Fatoş Ersoy (İstanbul: İletişim Yayınları, 1991). 
yönlendirmektedir. Tüketimin temelinde yer alan arzular, özellikle reklamlar aracıllğıyla oluşturulmakta ve dürtülenmektedir. Reklamlar, arzular oluşturarak yeni tüketiciler yaratmakta ve tüketimin devamlılığını sağlamaktadır. Tüketim arzularının reklamlar aracılığıyla sürekli yenilenmesi, bireylerin kimliklerini ve yaşam hedeflerini tüketim kalıpları üzerinden tanımlamalarına ve sürdürmelerine yol açmaktadır. Bireyler arzu ettikleri deneyimleri karşılamaya ekonomik güçleri yetmese de tüketici olmayı istemeye devam etmekte; kendi kimliklerini yeniden oluşturmalarına yardımcı olacağını düşündükleri tüketim nesnelerine yönelmektedir. Böylece tüketim, reklamlar aracılığıyla hem kolektif hem de bireysel kimlik duygularının sembolik oluşumunu içeren etkin bir sürece dönüşmektedir. ${ }^{40}$ Reklamlar ayrıca bireylere belli bir imaj oluşturmak için ne çeşit metaların tüketilmesi gerektiği hakkında bilgi sunmakta; moda yani kolektif bir davranış biçimi oluşturmaktadır. $\mathrm{Bu}$ bakımdan reklamlar, sadece ürünlerin pazarlanması için ekonomik bir araç olarak değil; bir toplumsal kontrol aracı olarak da işlev görmektedir. ${ }^{41}$

Reklamlar, bireylerin popüler ürün hakkında düşünmesini değil, onları popüler ürünü neden alması gerektiğine ikna etmeyi ve ürünün piyasadaki değerini artırmayı hedeflemektedir. Bireyleri popüler ürüne ikna etme ve ürünün piyasadaki değerini artırma hedefini gerçekleştirmek üzere reklamlar, potansiyel alıcı kitlesine göre uyarıcılar oluşturmaktadır. Bireylerin inanç ve değerler dünyası ile satın alma faaliyetleri arasındaki bağın farkında olarak pazarlama stratejileri geliştirmektedir. Reklamlarda göstergeler, bireylerin toplumsal kimliklerini ve değerlerini bulabilmelerini olanaklı kılacak ve kendilerine seslenildiği imajı oluşturacak şekilde düzenlenmektedir. ${ }^{42}$ Toplumun kültürel kodlarını, dini değer ve inançlarını çağrıştıran semboller popüler kültür ürünlerine işlenerek bireylerle ürünler arasında bir aidiyet hissi oluşturulmaktadır. Bireylerin inanç, değer ve duygu dünyalarına hitap edilerek popüler kültür ürünleri arzulanır ve tercih edilir hale getirilmektedir. Bu bakımdan dini semboller, reklam sektöründe yüksek kâr marjına sahip yatırım alanlarından biri olarak görülmektedir.

Endüstrinin üslubunu sergileyen reklamlar aracılığılyla dini semboller, tüketim terminolojisi içindeki yerini alarak kâr güdüsü temelinde metalaşmakta; markalaşarak endüstriyel pazara olabildiğince işlevsel bir biçimde uyarlanmaktadır. Reklamlarda popüler kültür ürünlerine eklemlenen dini semboller, çoğunlukla gerçek bir gereksinimi karşılamaya yönelik değil; pazarda kâr getirme odaklı

40 Robert Bocock, Tüketim, çev. İrem Kutluk (Ankara: Dost Kitabevi Yayınları, 1997).

41 Arthur Asa Berger, Kültür Eleştirisi Kültürel Kavramlara Giriş, çev. Özgür Emir (İstanbul: Pinhan Yayınc1lik, 2014), 63-64.

42 Mete Çamdereli, “Reklamın R'si ya da Reklam Söylemine Giriş”, İstanbul Üniversitesi İletişim Fakültesi Dergisi 2 (2012): 459-460. 
sergilenmektedir. Estetize edilerek arzu nesnesi haline getirilen dini semboller, bireylerin inanç ve değer dünyalarını yansıtan araçlar olarak sunulmaktadır. Böylece tüketici sayısı artırılmakta ve piyasa döngüsü dinamikleştirilmektedir. Reklamlar aracılığıyla popüler formların içine yerleştirilen dini semboller, rekabet ve pazar mantığının işlediği döngüde yeni içeriklerle tekrar üretilip tüketilir hale gelen tüketim nesnelerine dönüşmekte; popülerleşerek özünü kaybetmektedir.

\section{Göstergebilim ve Reklam}

Göstergebilim, göstergeleri inceleyen, göstergelerin niteliğini ve hangi yasalara bağlı olduğunu araştıran bilimdir. ${ }^{43}$ Göstergebilim, tüm özdekleri (ses, görüntü, nesne, yazı vb.) aşarak göstergeleri anlama, anlamlama ${ }^{44}$ ve açığa çıkarma etkinliğidir. Bir göndericiyle bir alıcı arasında bildiri alışverişinin olduğu yani anlama ve anlamlama eyleminin olduğu her yerde göstergebilimsel etkinlik karşımıza çıkmaktadır. Barthes, toplumsal yaşamda karşı karşıya kaldığımız çok geniş bir olgular bütününü, anlam taşıması ve anlamlama eylemine konu olması bakımından göstergebilimin yönelebileceği bir düzlem olarak görmektedir. ${ }^{45}$ Nitekim Pierre Guiraud'a göre de her şey bir göstergedir; her şey bir gösterilen, her şey bir gösterendir. ${ }^{46}$

Göstergebilim, bağımsız bir bilim değildir; disiplinlerarası bir nitelik arz etmektedir. Barthes, göstergebilimin çeşitli disiplinlerle ilişkisinin olduğunu ve disiplinlerin de göstergebilimden yararlanarak kendi perspektifinin farklılığını ortaya koyabileceğini belirtmektedir. ${ }^{47} \mathrm{Bu}$ bağlamda din sosyolojisi ve göstergebilim ilişkisini ele alan Okutan, göstergebilimin din sosyolojisi çalışmalarına katkıda bulunacağına işaret etmektedir. Okutan'a göre din sosyolojisi çalışmalarında göstergebilim, dini sembollerin değişen ve dönüşen kültürel formlarının arka planını çözümlemeye olanak sağlayacak bir yöntem olarak karşımıza çıkmaktadır. ${ }^{48}$ Din ve bir kültür endüstrisi aracı olarak reklam ilişkisini din sosyolojisi disiplini çerçevesinde ele almaya çalışan bu çalışmada göstergebilimsel çözümleme yönteminden yararlanılmaktadır.

Göstergebilimin temel kavramı göstergedir. ${ }^{49}$ Gösterge, kendi dışında bir nesne, olgu ya da varlık belirtebilen ögedir. Bu öge, bir uyarıcıdır; bir anlam çağrıştırma

43 Pierre Guiraud, Göstergebilim, çev. Mehmet Yalçın (Ankara: İmge Kitabevi, 1994), 17-18.

44 Anlamlama, bir göstergede gösteren ile gösterilen arasında bir ilişki kurulmasını ifade etmektedir.

45 Barthes, Göstergebilim Illkeleri, XV.

46 Guiraud, Göstergebilim, 58.

47 Barthes, Bir Deneme Bir Ders: Eiffel Kulesi ve Açılış Dersi, 60.

48 Okutan, Din Sosyolojisi ve Göstergebilim, 9.

49 Guiraud, Göstergebilim, 8. 
ya da anlam iletme işlevi görmektedir. Uyandırdığı imge, zihinde başka bir uyarıcının imgesine bağlanmakta; bir iletişim doğrultusunda bu ikinci imgeyi canlandırmaktadır. ${ }^{50}$ Dolayısıyla göstergede iki yönlü bir ilişki söz konusudur: Bir gösteren ile bir gösterilen. Bu bağlamda gösterge, gösteren ile gösterilen arasındaki ilişki üzerine kuruludur. ${ }^{51}$ Barthes'e göre gösteren düzlemi, göstergenin anlatım düzlemine; gösterilen düzlemi ise göstergenin içerik düzlemine işaret etmektedir. ${ }^{52}$

Göstergenin iki temel ögesinden biri olan gösteren, nesnenin fiziksel gerçekliğidir. Göstereni gösterilenden ayıran temel özellik, gösterende bir özdek (ses, görüntü, nesne, yazı vb.) bulunması zorunluluğudur. ${ }^{53}$ Gösteren, "gösterilen üzerine örtülen ve ona biçimini veren bir 1zgara gibidir"; ${ }^{4}$ özdeksel yapısı ile gösterilene aracılık etmektedir. Gösterilen ise nesnenin fiziksel gerçekliği değil; göstergeyi kullananın ondan anladığ 1 şeydir. Gösterilenin bir nesne ya da anlıksal bir tasarım olup olmadığ 1 konusunda Barthes anlıksal tasarımı, gerçek nesneyi ve söylenebilir'i birbirinden ayıran Stoacıların çözümlemesini benimsemekte; gösterilenin tasarım ya da gerçek bir nesne olmadığını belirtmektedir. Barthes'e göre gösterilen, bilinç edimi ya da gerçek bir nesne olmayıp söylenebilir'dir. Bu bakımdan gösterilen, göstergeyi kullananın ondan anladığı şey olarak tanımlanabilir. ${ }^{55}$ Gösterilen düzleminin farklı biçim ya da derinlikte kavranıp çözümlenmesi, okurların farklı türden bilgileri ya da kültürsel farklılıklarından kaynaklanmaktadır. ${ }^{56}$ Barthes gösterilenleri, özgürlüklerine kavuşturulması gereken esirlere benzetmekte ve gösterilenleri çözümlemenin önemine işaret etmektedir:

"Söz güçlerinin o büyük oyununda da esir kapmaca oynanır: Bir dilin bir başka dil üstünde ancak geçici bir üstünlügü̈ vardır; saldırganın geri çekilmek zorunda kalması için üçüncü bir dilin ortaya çıkması yeterlidir: Retorikler çatışmasında, zaferi kazanan yalnızca üçüncü dil olur. Bu dilin görevi, esirleri özgürlüğe kavuşturmaktır: Yani gösterilenleri dağıtmaktır." ${ }^{\circ 7}$

Göstergeler gösterme, bildirme, yönlendirme ve benimsetmeye yönelik karşımıza çıkmaktadır. Bireyler de göstergelerde sunulan imge, fikir ya da mesajı vs. farkında olmadan kabul etmek durumunda kalmaktadır. Bu durum kültür endüstrisinin

50 Guiraud, Göstergebilim, 39.

51 Guiraud, Göstergebilim, 41.

52 Barthes, Göstergebilim Illkeleri, 31.

53 Barthes, Göstergebilim Illkeleri, 40.

54 Guiraud, Göstergebilim, 52.

55 Barthes, Göstergebilim Illkeleri, 35.

56 Barthes, Göstergebilim Illkeleri, 40.

57 Roland Barthes, Yaşantı, çev. Sema Rifat (İstanbul: Yapı Kredi Yayınları, 1998), 63-64. 
en önemli anlatım ve aktarım araçlarından biri olan reklam göstergeleri için düşünüldügünde daha da anlamlı hale gelmektedir. Reklam göstergeleri, bireylere farkında olmadan kabul etmek durumunda kaldıkları anlamlar, imgeler ve mesajlar sunmaktadır. Gösterilmesi gerekeni, göstermeyecek ya da anlamsızlaştıracak bir şekilde göstermekte; Bourdieu'nun tabiriyle "göstererek gizleyebilmektedir." ${ }^{58} \mathrm{Bu}$ bakımdan reklam göstergeleri, göstergebilimin en önemli çözümleme birimlerinden birini oluşturmaktadır.

Göstergebilim bir yöntem olarak reklam göstergelerinde bireylere sunulan anlamların, imgelerin ve mesajların gerçekte nelere işaret edebileceğine ve bireyleri hangi açılardan nasıl etkileyebileceğine yönelik çözümlemelere katkı sağlamaktadır. $\mathrm{Bu}$ çalışma da göstergebilimi bir yöntem olarak kullanmakta; kültür endüstrisi bağlamında reklam ve din ilişkisini göstergebilimsel çözümleme yönteminden yararlanarak ele almayı amaçlamaktadır. Çalışmanın bir sonraki bölümünde çalışmanın amacı ile uygunluk gösteren ve temel problemlerin farklı yönleri ile ele alınmasına olanak sağlayan on reklam göstergesi, Barthes'in göstergebilimsel çözümleme yöntemi kullanılarak analiz edilmektedir.

\section{Reklam Göstergelerinin Göstergebilimsel Çözümlemesi}

Çalışmanın bu bölümünde örnekleme yöntemi doğrultusunda seçilen reklamlarda kültür endüstrisine dair içerikler tespit edilmeye çalışılacak; göstergelerin nasıl sunulduğu, dini sembollerin popüler kültür formları ile nasıl ilişkilendirildiği ve göstergelerin sunulanın dışında başka nelere işaret edebileceği gösteren-gösterilen düzlemleri üzerinden çözümlenecektir.

\section{Gösterge 1}
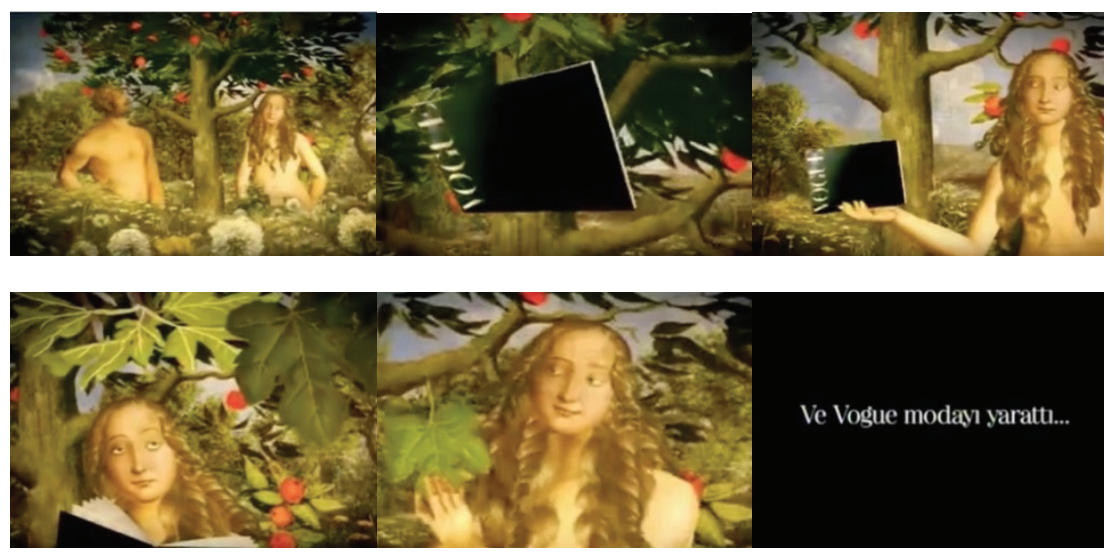

58 Pierre Bourdieu, Televizyon Üzerine, çev. Turhan Ilgaz (İstanbul: Yapı Kredi Yayınları, 1997), 23. 
Gösteren: Âdem ve Havva figürü, meyve ağac1, Vogue, ${ }^{59}$ düşünceli yüz ifadesi (Havva figürü), yaprak, mutlu yüz ifadesi (Havva figürü), yazı tümcesi "Ve Vogue modayı yaratt1...".

Gösterilen: Giyinen ilk kadın olarak dini bir sembol Havva, insanın varoluşundan bu yana modanın varlığına işaret, kadının modaya olan ilgisi, derginin modanın tanrıs1 olduğuna vurgu.

Çözümleme: Moda dergisi Vogue için animasyon tekniği ile hazırlanan reklam filminde, dini bir sembol olan Âdem ve Havva'nın yasaklanan meyveyi yedikten sonra çıplak olduklarını anlayarak mahrem yerlerini kapatma çabasına girdikleri rivayetinden yola çıkılmaktadır. Reklamda Havva figürü, -yasak meyve olarak algılanabilecek- meyve ağacının altında bulunan Âdem figürünün yanına gelmekte; ardından Vogue, Âdem figürünün değil, Havva figürünün eline düşmektedir. Kadının modaya olan ilgisi, göstergede dini bir sembol olan Havva üzerinden tekrar işlenmektedir. Düşünceli ifadelerle dergiyi inceleyen Havva figürü, ağaç yaprağını görmekte; bu sırada iki figür de gülümsemektedir. Havva figürünün yaprağ 1 kopararak mahrem yerini kapatmasının ardından "Ve Vogue modayı yarattı..." sloganı belirmektedir. Giyinen ilk kadın olarak Havva gösterimi, insanın varoluşundan bu yana modanın varlığına işaret etmektedir. Slogan ile derginin modayı yaratarak modanın tanrısı olduğuna vurgu yapılmaktadır. İlk kadın Havva'nın giyinmesine öncülük eden Vogue, modayı yarattığı iddiasını pekiştirmekte; Âdem ve Havva sembolleri ise popüler endüstride tüketilir hale gelmektedir.

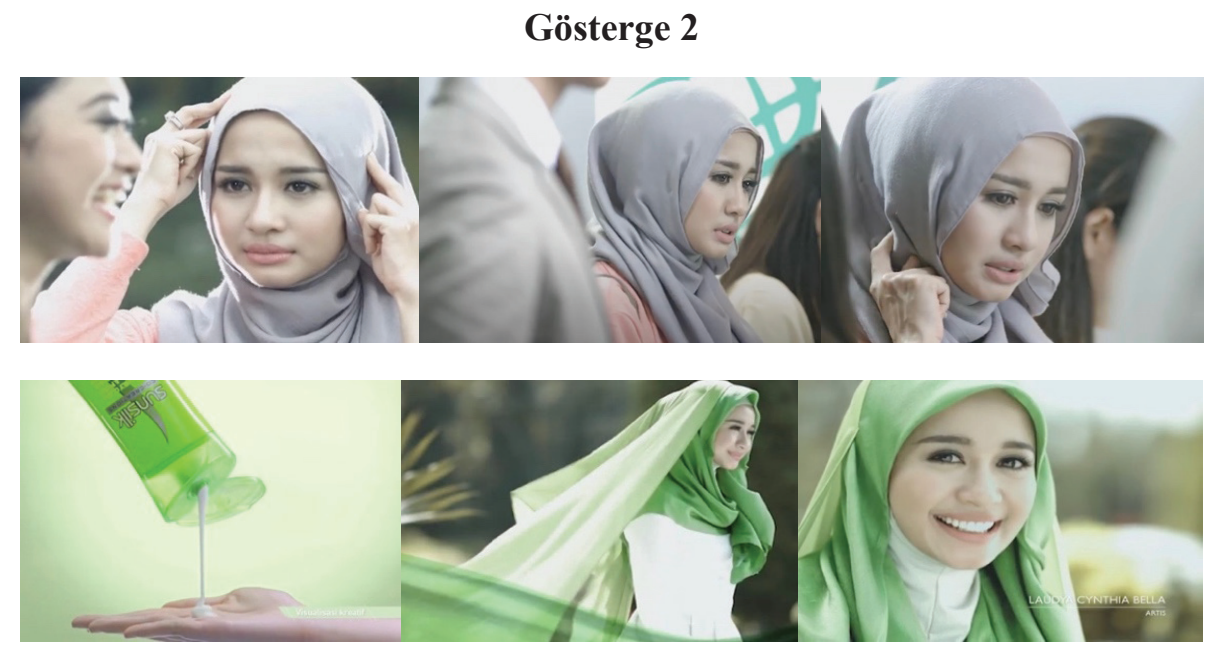

59 Moda dergisi, https://vogue.com.tr (Nisan 3, 2020). 
Gösteren: Laudya Cynthıa Bella (aktris), gri renk başörtüsü, kapalı mekân (asansör), üzgün ve özgüvensiz yüz ifadesi, Sunsilk Clean and Fresh şampuan, yeşil renk başörtüsü, açık hava, esinti, mutlu ve özgüvenli yüz ifadesi, gülümseme.

Gösterilen: Ünlülük, tanınırlık, popülerlik, genç ve sağlıklı görünüm, başörtüsünün saç ile özdeşleşimi, gri rengin başörtüsü ile eklemlenerek cansızlık ve devinimsizliğe işareti, yeşil rengin başörtüsü ile eklemlenerek yeşil ambalajlı Sunsilk şampuanı tamamlayacak şekilde canlılık ve dinamizme işareti, keyifli bir gün, ferahlık, bakımlı olmak, özgüvenli olmak.

Çözümleme: Sunsilk şampuan firması için hazırlanan reklam filmi temelde kadının kendine olan güveninin Sunsilk Clean and Fresh şampuan ile sağlanabileceğini vurgulamaktadır. Dikkat çeken husus, şampuan reklamında başörtülü bir modelin kullanılması ve başörtüsünün saç ile özdeşleştirilmesidir. Göstergelerde popüler bir aktris olan Laudya Cynthı Bella ile başörtüsünün ön planda ve netleştirilerek odak noktasına alındığı, arka planda kalan kısımların bulanıklaştırıldığı görülmektedir. Netleştirme tekniği, reklam göstergelerinde oluşturulmak istenen anlam açısından önemli bir role sahiptir. Teknik ile odaktaki kişi, nesne ya da semboller netleştirilerek izleyicinin dikkati ve algısı yönlendirilmektedir. Göstergeler incelendiğinde, odak noktasında olan Laudya Cynthıa Bella hem ünlülük, tanınırlık ve popülerliğe hem de genç ve sağlıklı görünüme işaret etmektedir. Toplumsal ortamda üzgün ve özgüvensiz tavırlarla görsele yansıyan model, odakta saç ile özdeşleştirilen başörtüsünü ufak dokunuşlarla hareket ettirmeye çalışmaktadır. Sunsilk Clean and Fresh şampuan tanıtımının ardından model, açık mekânda yeşil renk başörtüsüyle görsele yansımaktadır. Kapalı mekân-açık mekân karşıtlığı kullanılan göstergede açık hava keyifli bir güne, mutluluk ve neşeye; başörtüsüne verilen esinti ferahlığa işaret etmektedir. Reklam filminde, Sunsilk Clean and Fresh şampuan ile bakımlı olmak ve özgüvenli olmak arasında bir ilişkilendirme ve anlam aktarımı söz konusudur. Şampuan ile model, daha canlı bir görünüme kavuşmakta ve kendine güven duymaktadır. Reklamda gösterilenler açısından önemli noktalardan bir diğeri, başörtüsü ile eklemlenerek kullanılan renklerdir. Reklamda gri renk, başörtüsü ile eklemlenerek cansızlık ve devinimsizlikle ilişkilendirilmekte; yeşil renk, yine başörtüsü ile eklemlenerek yeşil ambalajlı Sunsilk şampuanı tamamlayacak şekilde canl1l1k ve dinamizme işaret etmektedir. ${ }^{60}$ Ancak burada söz konusu olan renkler değil; soyut anlamlardır. Baudrillard'ın tabiriyle "renkler, kendilerine yüklenen soyut anlamlara boyun eğmek durumunda kalmakta, önceden belirlenmiş belli kültürel anlamları dolaylı bir şekilde yansıtmaktadır. Hem birbirleriyle hem de ilgili nesne ya da sembol ile zorunlu bir ilişki içine giren renkler, kendilerine yüklenen

60 https://www.arkhesanat.com/renklerin-anlami/ (Nisan 10, 2020). 
soyut anlamları dolaylı bir şekilde yansıtarak işlevselleşmektedir." ${ }^{11}$ Reklamda saç ile özdeşleştirilen ve renkler ile eklemlenerek kullanılan başörtüsü hem cansızlık ve devinimsizlik hem de canlılık ve dinamizm göstergesi olarak sunulmaktadır.

\section{Gösterge 3}

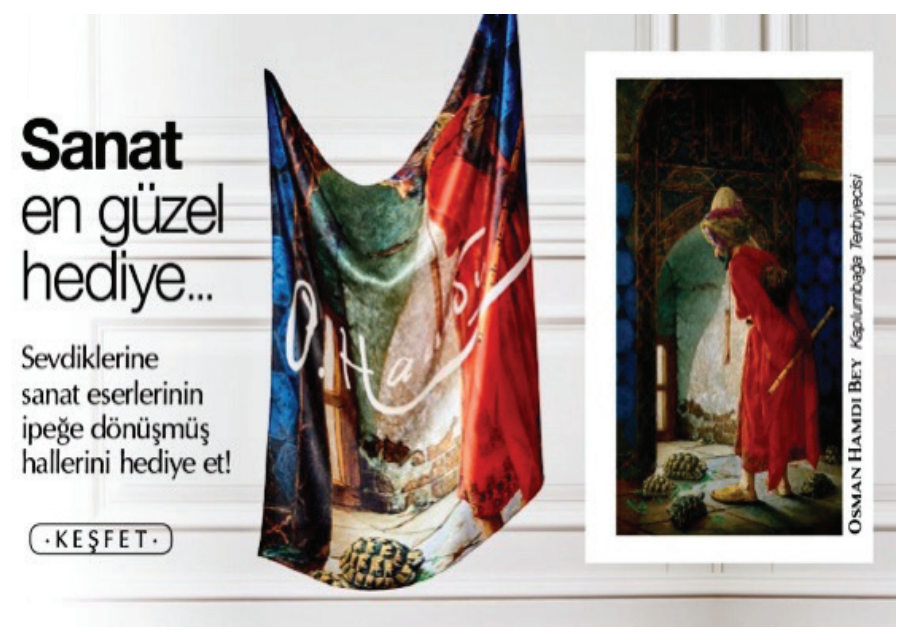

Gösteren: Yazı tümcesi (başlık) "Sanat en güzel hediye...", (gövde metin) "Sevdiklerine sanat eserlerinin ipeğe dönüşmüş hallerini hediye et! KEŞFET", OSMAN HAMDİ BEY Kaplumbağa Terbiyecisi.

Gösterilen: Başörtüsü, endüstrinin üslubunu sergileyen bir nesne halindedir. ${ }^{62}$

Çözümleme: Kültür endüstrisi ile birlikte sanat eserleri de metalaşmakta; sanatın kullanım değeri, mübadele değeriyle ikame edilir hale gelmektedir. ${ }^{63}$ Piyasa kurallarına bağlı bir şekilde metalaşan sanat, kitleler tarafindan kullanılarak popülerleşmektedir. Bir yüksek kültür ürünü olan Osman Hamdi Bey'in "Kaplumbağa Terbiyecisi" tablosu da kültür endüstrisi ile birlikte metalaşmış bir şekilde karşımıza çıkmaktadır. Türkiye'de çok yüksek bir bedelle ${ }^{64}$ satışı yapılan "Kaplumbağa Terbiyecisi",

61 Jean Baudrillard, Nesneler Sistemi, çev. Oğuz Adanır - Aslı Karamollaoğlu (İstanbul: Boğaziçi Üniversitesi Yayınevi, 2010), 40-45.

62 Reklam göstergesinde Kaplumbağa Terbiyecisi eşarbın salt dini bir sembol -başörtüsü- olarak değil; bir aksesuar olarak satışa sunulmakta olduğu öne sürülebilir. Kemer, bileklik, çanta üstü fular vs. şeklinde bir aksesuar olarak kullanılmakla birlikte (https:/www.hepsiburada.com/ kesfet/esarplari-sandiktan-cikarin-yaratici-esarp-baglama-metodlari/ Nisan 19, 2020) eşarplar, genellikle tesettür ile bağdaştırılmakta ve başörtüsü olarak kullanılmaktadır. Bu bakımdan göstergenin gösterilen ve çözümleme kısmında Kaplumbağa Terbiyecisi eşarp, dini sembol -başörtüsü- olarak ele alınmaktadır.

63 Adorno - Horkheimer, Aydinlanmanın Diyalektiği, 211.

64 https://arkeofili.com/osman-hamdi-beyin-tablosu-acik-artirmada-satildi/ (Nisan 19, 2020). 
endüstri ile birlikte kol saati, ${ }^{65}$ kolye, ${ }^{66}$ hall, ${ }^{67}$ dekoratif yastık, ${ }^{68}$ puzzle ${ }^{69}$ vs. üzerine işlenerek satışa sunulmaktadır. Bu ürünleri satın alan kişilerin görünüşte aldıkları zevk, iki fantasmadan ${ }^{70}$ ileri gelmektedir: Ürünü satın alan kişi, tablonun indirgenmiş biçimine sahip olmakla onu elinde tutma şansını elde etmektedir. Tablonun gerçek değerini yapan şey, bir bakıma tüketicinin elinin altındadır. Tüketici, ulaşılamaz ve sahip olunamaz nitelikli tabloyu kendi gündelik yaşamına katabilecek duruma gelmektedir. Tablonun görüntüsü artık mülkiyet dışıdır; o, herkese aittir. Reklam göstergesinde ise "Kaplumbağa Terbiyecisi”nin ipek eşarp üzerine işlenmiş olduğu görülmektedir. Göstergede başörtüsü, endüstrinin üslubunu sergileyen bir nesne halindedir; tüketicinin ulaşılamaz ve sahip olunamaz nitelikli tabloyu gündelik yaşamına katmasına ve tablonun indirgenmiş biçimine sahip olmasına yönelik bir fantasmaya da arac1lık etmektedir. Reklam gövde metninde, "Sevdiklerine sanat eserlerinin ipeğe dönüşmüş hallerini hediye et! KEŞFET", tanıtım metninde "Osman Hamdi Bey’in en çok ilgi çeken ve özgün eserlerinden Kaplumbağa Terbiyecisi, Türkiye'nin en özel ve satışı en yüksek bedelle yapılan eseridir. Eserde Osman Hamdi'nin kendisi olan Terbiyeci elinde neyi, boynunda mızrabı, sırtında nakkaresi ile hafif öne eğilmiş olarak yaprakları yiyen üç kaplumbağa nezaret etmektedir. Mekân ise Bursa'daki Yeşil Cami'dir ve Osman Hamdi birçok eserinde kendini de figür olarak resmetmiştir. Gardırobunuzda sanata yer açın! Stilinize özgün ve farklı dokunuşlar yapmanın gizli formülü burada gizli..."”1 mottoları ile "iknanın heyecanı, nesneye ve nesnenin söylemine aktarılmaktadır." ${ }^{\text {72 }}$

65 https://www.gittigidiyor.com/taki-saat/kaplumbaga-terbiyecisi-vintage-tasarim-saat-1ad_ pdp_171999380 (Nisan 19, 2020).

66 https://www.trendyol.com/pivada/kolye-osman-hamdi-bey-kaplumbaga-terbiyecisi-p38782096 boutiqueId $=316846 \&$ merchantId $=125647$ (Nisan 19, 2020).

67 https://www.trendyol.com/rugviva/kaymaz-tabanli-makinede-yikanabilir-hali-rv358-kaplumbagaterbiyecisi-p-42568989?boutiqueId=528092\&merchantId=106268\&gads=true (Nisan 19, 2020).

$68 \mathrm{https} / /$ www.hepsiburada.com/realhomes-kaplumbaga-terbiyecisi-dijital-baskili-dekoratif-yastikkirlent-kilifi-p-HBV000001TCS6?magaza=RealHomes\&wt_gl=cpc.6820.shop.nelk.ev-tekstil-ss c\&isFashion=true\&gclid=Cj0KCQiA34OBBhCcARIsAG32uvNHeY_DF-30GuTjaLBRQ71o 4WuzmZ3jnDFAu0YWxAXku3pDOLPRrXIaAm_5EALw_wcB (Nisan 19, 2020).

69 https://www.puzzlesepeti.com/urun/4452-art-puzzle-1000-parca-puzzle-kaplumbaga-terbiyecisi (Nisan 19, 2020).

70 Fantasme [phantasme], gerçekte var olmadığı halde gözün var gibi gördüğü imge, görme yanıltısı.

71 https://www.ipekevi.com/kaplumbaga-terbiyecisi-saten-ipek-esarp-0111301005090 (Nisan 4, 2020).

72 Jean Baudrillard, Tüketim Toplumu, çev. Hazal Deliceçaylı - Ferda Keskin (İstanbul: Ayrıntı Yayınlar1, 2013), 140. 


\section{Gösterge 4}

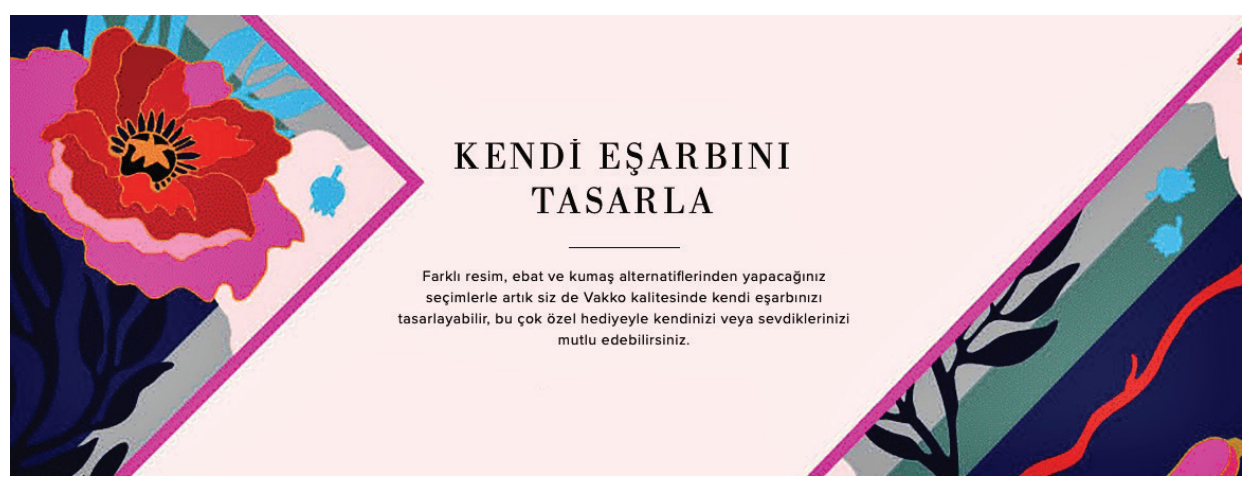

Gösteren: Yazı tümcesi (başlık) "KENDİ EŞARBINI TASARLA", (gövde metin) "Farklı resim, ebat ve kumaş alternatiflerinden yapacağınız seçimlerle artık siz de Vakko kalitesinde kendi eşarbınızı tasarlayabilir, bu çok özel hediyeyle kendinizi veya sevdiklerinizi mutlu edebilirsiniz."

Gösterilen: Eşarbını kendi seçimleriyle tasarlayan birey, kendini mutlu edecektir.

Çözümleme: Popüler kültürde birey kendine döndürülmekte; bireysel tüketmeye ve kullanmaya dayalı özgürlükler işlenmektedir. ${ }^{73}$ Reklam göstergesinde de "Kendi Eşarbını Tasarla" mottosu ile bireyin kişiselliğine vurgu odaklı bir pazarlama stratejisi kullanılmakta, bireysellik tekniği ${ }^{74}$ ile her bireyin özel olduğu izlenimi verilmekte ve bireye tasarladığı eşarp üzerinden bir tatmin vaadi oluşturulmaktadır. Birey farklı resim, ebat ve kumaş alternatiflerinden yararlanarak eşarbını istediği formda tasarlayabilecek; tasarladığı eşarp ile kendi niteliklerini ön plana çıkarabilecektir. Bu noktada başörtüsü, bireyin öznelliğini ve farklılığını ortaya koymasına aracılık etmekte; aynı zamanda bireyin kendisini özel, farklı ve mutlu hissetmesine yönelik bir tatmini yerine getirmektedir. Böylece sembol, bireyin özünde aynılaştı̆̆ toplumsalın içinde kendini farklı olarak tanımlamasına olanak sağlayan bir tüketim nesnesine dönüşmektedir.

73 İrfan Erdoğan - Korkmaz Alemdar, Popüler Kültür ve İletişsim (Ankara: Erk Yayınları, 2005), 51.

74 Adorno, Kültür Endüstrisi Kültür Yönetimi, 112. 


\title{
Gösterge 5
}

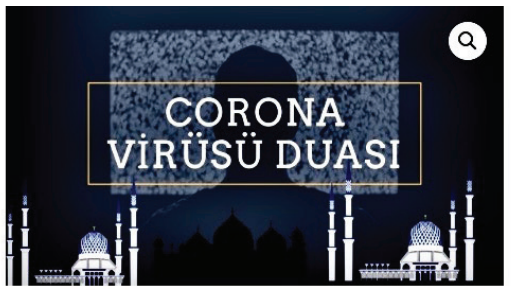

\section{Corona Virüsünden Koruma Duası}

\author{
$€ 20.00$ \\ BAĞISIIN KADAR VIRÜSTEN KORUN VE SEVDIKLERINDE \\ KORUNSUN!! \\ CORONA VÜRÜSÜ ÜLKEMIZDEDE GÖRÜLMEYE BAȘLANDI \\ EĞER KORUNMAK VE AILENI KORUMAK ISTIYORSAN BU \\ DUA'YA IHTIYACIN VAR. NE KADAR ÇOK BAĞIŞ SENI O KADAR \\ KORUR VE DIĞER HASTALIKLARDAN DA ARINDIRIR.

Gösteren: Cami görseli, yazı tümcesi (başlık) "CORONA VİRÜSÜ DUASI", (büyük harf kullanımıyla gövde metin) "Bağışın kadar virüsten korun ve sevdiklerin de korunsun.! Corona virüsü ülkemizde de görülmeye başlandı. Eğer korunmak ve aileni korumak istiyorsan bu duaya ihtiyacın var. Ne kadar çok bağış seni o kadar korur ve diğer hastalıklardan da arındırır."

Gösterilen: "Corona Virüsü Duası" bağışında bulunan kişi hem kendisini hem de sevdiklerini virüsten koruyacaktır.

Çözümleme: Kültür endüstrisi, ürettiği standart ürünlerin tüketicilerin ihtiyaçlarından kaynaklandığını öne sürmektedir. ${ }^{75}$ Tüketicilere de bu ürünleri satın alarak ihtiyaçlarını karşılayabileceklerini vaat etmektedir. Gerçekte ise endüstri, herkes için uygun bir şeyler öngörüp ${ }^{76}$ ihtiyaçlar üretmekte; ürettiği tüketici ihtiyaçlarını öngörülen ürünlerle karşılamaya çalışarak bireylerde aldatıcı bir memnuniyet duygusu ve ikame bir doyum oluşturmaktadır. ${ }^{77}$ İkame doyum, tekrar bireyleri yönlendirmekte ve bu düzenlenmiş etkinlikle sistemin devamlılığ1 pekişmektedir. Reklam göstergesinde de sistemin devamlılığ için bir ihtiyaç üretilmekte; üretilen ihtiyacı gidermenin yolu gösterilerek bireylerde bir plasebo etkisi ${ }^{78}$ oluşturulmaya çalışılmaktadır: "Corona virüs, ülkemizde de görülmeye başland1. Kendini, aileni ve sevdiklerini koruman gerekiyor. Virüsten korunmak için Corona Virüsü Duası'na ihtiyacın var. 20 £ karşılığında dua bağışında

75 Adorno - Horkheımer, Aydınlanmanın Diyalektiği, 163.

76 Adorno - Horkheımer, Aydınlanmanın Diyalektiği, 166.

77 Adorno, Kültür Endüstrisi Kültür Yönetimi, 119.

78 Plasebo etkisi, farmakolojik olarak etkisiz bir ilacın, telkine dayalı olarak bir etki ortaya çıkarması halidir. Plasebonun fiziksel anlamda tedavi gücü ve etkisi yoktur. Gücünü, hastanın verilen ilacın işe yarayacağına ve tedaviyi gerçekleştireceğine psikolojik olarak inanmasından almaktadır. Baudrillard, Nesneler Sistemi, 204. 
bulun. Ne kadar dua bağışında bulunursan virüsten o kadar korunacaksın ve diğer hastalıklardan da arınacaksın." Göstergede satın alma faaliyeti, "bağış" adı altında gerçekleştirilmekte; tüketiciden "bağış" adı altında alışveriş malzemesine dönüştürülen duayı satın alması talep edilmektedir. Endüstri ile birlikte kâr güdüsü temelinde metalaşarak kullanıma hazır hale getirilen dua, reklam göstergesinde hem alınıp satılabilen bir tüketim nesnesi hem de tüketiciyi satın alma faaliyetine yönelten bir güdümleme nesnesi olarak işlev görmektedir.

\section{Gösterge 6}

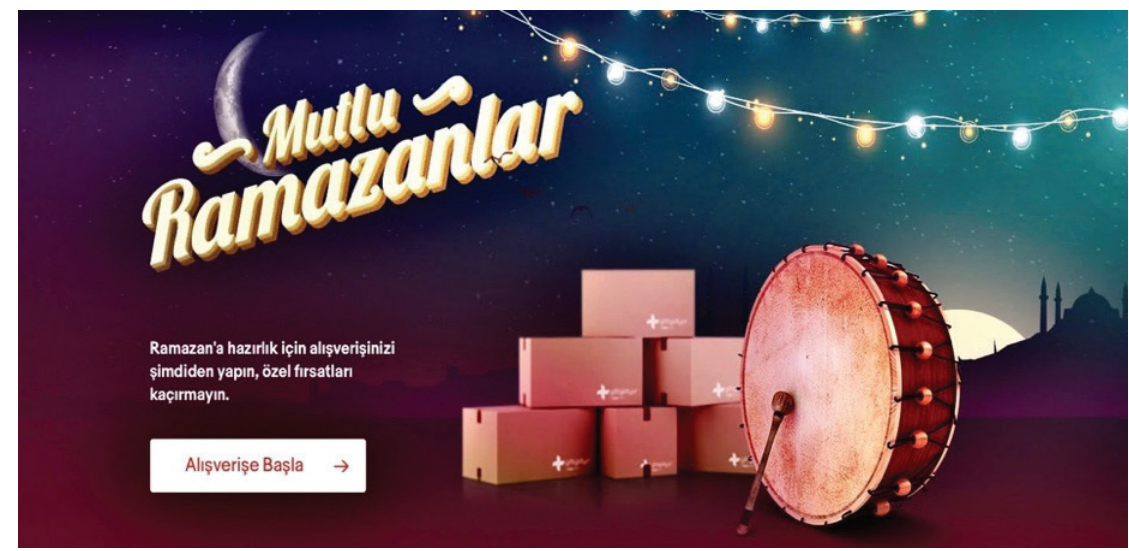

Gösteren: Davul ve tokmak, koliler, mahya, cami, hilâl, yazı tümcesi (başlık) "Mutlu Ramazanlar”, (gövde metin) "Ramazan’a hazırlık için alışverişinizi şimdiden yapın, özel fırsatları kaçırmayın. Alışverişe Başla."

Gösterilen: İlgili sitenin Ramazan ayına özel sunduğu firsatlardan yararlanarak alışveriş yapan kitle, mutlu bir Ramazan geçirecektir.

Çözümleme: Reklam göstergesinde Ramazan ayının davul, tokmak, Ramazan kolileri, mahya, cami ve hilâl ${ }^{79}$ gibi sembolik unsurları, alıcıların tüketim isteğini harekete geçirmeye yönelik bir gösterge olarak sunulmaktadır. Reklamın temelinde Ramazan ayı, bir tüketim ve firsat ayı olarak tanıtılmakta; ilgili sitenin Ramazan ayına özel sunduğu firsatlardan yararlanarak alışveriş yapan kitlenin, mutlu bir Ramazan geçireceği vurgulanmaktadır. Gövde açılama metninde Ramazan ayı, "kampanya", "indirim", "fırsat", "avantaj" ile ilişkilendirilmekte ve alıcıları tüketime teşvik etmeye yönelik işlevselleştirilmektedir: "GittiGidiyor, ihtiyaçların artacağ1 Ramazan ayı için muhteşem bir kampanya düzenledi. En uygun fiyatı bulmak için market market dolaşıp satın aldığınız temizlik ve mutfak ürünleri GittiGidiyor

79 Hilâl, Ramazan ayının başlangıcı ve bitişini sembolize etmekte; yenilik, doğum, taze hayat, mutluluk, sevinç ve dirilişe işaret etmektedir. 
Ramazan kampanyasında rakipsiz fiyatlarla sizi bekliyor. Tüm ihtiyaçlarınızı en uygun fiyat ve kapınıza teslim avantajıyla sipariş edebilirsiniz. Üstelik ücretsiz kargo ve taksitli ödeme avantajlarıyla." ${ }^{\text {00 }}$ Reklam retoriği içinde bir hizmet ve armağanmış gibi sunulan bu kampanya, indirim, fursat ve avantajlar vs. gerçekte bir gimmick ${ }^{81}$ olarak işlev görmekte; göstergede de dini bir sembol olarak Ramazan, pazar döngüsünü dinamikleştirmek için kullanılan gimmicklerle eklektik bir biçimde işlevselleştirilmektedir.

\section{Gösterge 7}

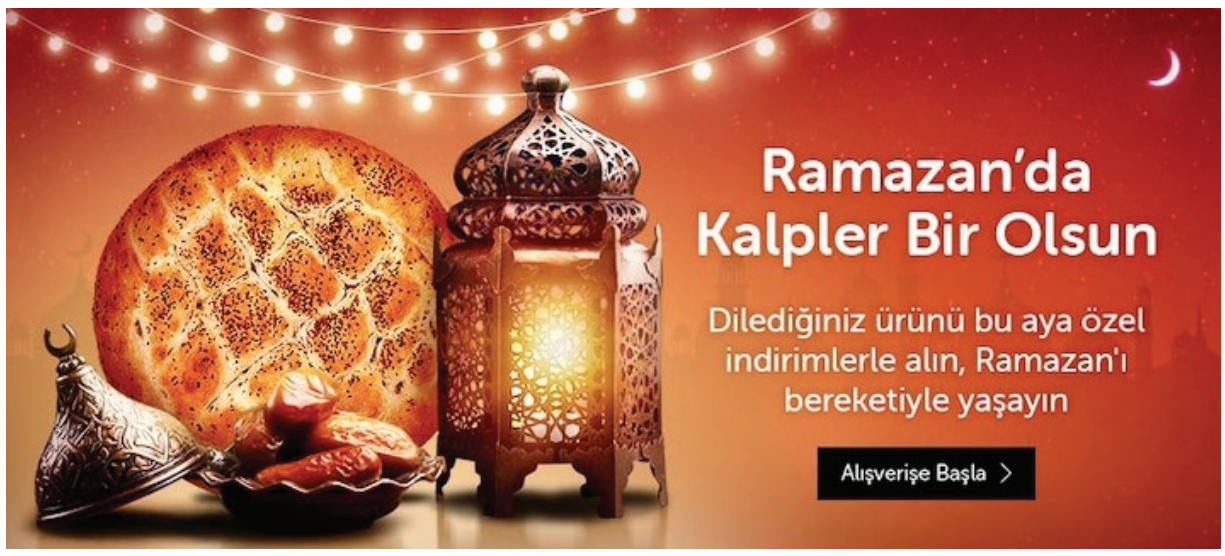

Gösteren: Ramazan pidesi, hurma, kandil, mahya, hilâl, yazı tümcesi (başlık) "Ramazan'da Kalpler Bir Olsun", (gövde metin) "Dilediğiniz ürünü bu aya özel indirimlerle alın, Ramazan’ı bereketiyle yaşayın. Alışverişe Başla."

Gösterilen: Covid-19 salgını nedeniyle Ramazan'da bir araya gelemeyen kitle, "Ramazan'da Kalpler Bir Olsun" mottosu ile çevrimiçi tüketime sevk edilmekte, Ramazan ayına özel indirimlerle Ramazan'ın bereketli geçeceği imlenmektedir.

Çözümleme: Reklam göstergesinde Ramazan ayının sembolik unsurlarından olan pide, hurma, kandil, mahya ve hilâl, alıcıların tüketim isteğini harekete geçirmeye yönelik bir gösterge olarak sunulmaktadır. "Ramazan'da Kalpler Bir Olsun" mottosu, Ramazan ayının birlik, beraberlik ve dayanışma ruhu ile ilişkilendirilmekte; temelde Covid-19 salgını nedeniyle Ramazan'da bir araya gelemeyen kitle, "bir araya gelinemese de kalpler bir olsun" imlemesiyle çevrimiçi tüketime sevk edilmektedir. Reklam gövde metninde "Dilediğiniz ürünü bu aya özel indirimlerle alın.” tümcesi ile indirimli ürünlerden yararlanma süresi, Ramazan

80 https://www.gittigidiyor.com/kampanya/ramazan-paketi (Nisan 26, 2020).

81 "Gimmick, satın almaya teşvik etmek için hazırlanan küçük tuzaklar." Baudrillard, Tüketim Toplumu, 195. 
ayı ile sınırlandırılmakta; Ramazan'ın aylık süreci piyasa kurallarına göre işler hale getirilmektedir. "Ramazan'ı bereketiyle yaşayın. Alışverişe Başla." tümcesi ile Ramazan'1n sembolik unsuru olan manevi bereketin anlamı, bol tüketimle özdeşleştirilmektedir.

\section{Gösterge 8}

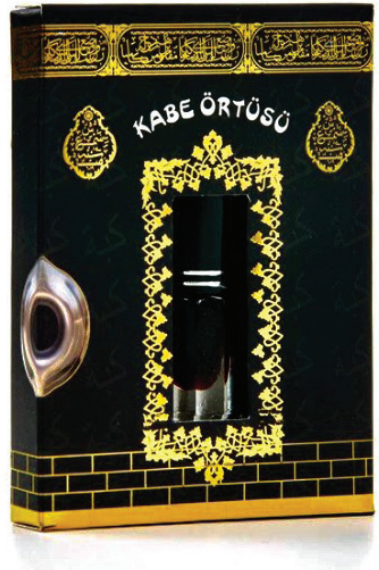

Kabe Örtüsü Esansı (Orijinal Kabe Örtü Kokusu)-5125

34,48 TL \& Ücretsiz Kargo

Hacim : Standart

(i) Tahmini Teslim Tarihi: 27 Ekim - 30 Ekim Aynı gün teslim ürünler için tıklayınız.

(U) Ocretsiz Kargo | శิ Güvenli Ödeme

Sipariș Ver

Gösteren: Yazı tümcesi (başl1k) "Kabe Örtüsü Esans1 (Orjinal Kabe Örtü Kokusu)".

Gösterilen: Kâbe Örtü Kokusu, "orijinal” etiketiyle sunulmaktadır.

Çözümleme: Göstergede dini bir sembol olarak Kâbe, paketlenebilen, alınıp satılabilen ve tüketilebilen bir meta halindedir. Popüler kültür ürününe işlenerek endüstrileşen Kâbe ile alıcıların inanç, değer ve duygu dünyalarına hitap edilmekte; alıcılarla ürün arasında bir aidiyet hissi oluşturulmaktadır. Kâbe Örtü Kokusu, endüstri tarafından gösterme ve elde tutulma özelliğine sahip bir meta halinde üretilerek tüketim âlemine yerleştirilmektedir. Reklamda ise alıcıların inanç dünyası ile satın alma faaliyetleri arasındaki ilişki merkeze alınarak ürünün piyasadaki değerini artırmaya yönelik bir pazarlama stratejisi kullanılmaktadır. Kâbe Örtü Kokusu, simüle edilmekte ${ }^{82}$ ve "orijinal" etiketi ile sunulmaktadır. "Orijinal" etiketi ile Kâbe Örtü Kokusu'nun meta niteliği geliştirilmekte ve ürün endüstriyel pazara olabildiğince işlevsel bir biçimde uyarlanmaktadır. "Orijinal” etiketi ayrıca alıcıları güdümlemeye ve tüketime ikna etmeye yönelik bir işlev görmekte; etiket ile alıcılarda bir güven duygusu oluşturularak ürün tercih edilir hale getirilmektedir.

82 "Simüle etmek, gerçek olmayan bir şeyi gerçekmiş gibi sunmak, göstermeye çalışmak." Jean Baudrillard, Simülakrlar ve Simülasyon, çev. Oğuz Adanır (Ankara: Doğu Batı Yayınları, 2011), 7. 


\section{Gösterge 9}

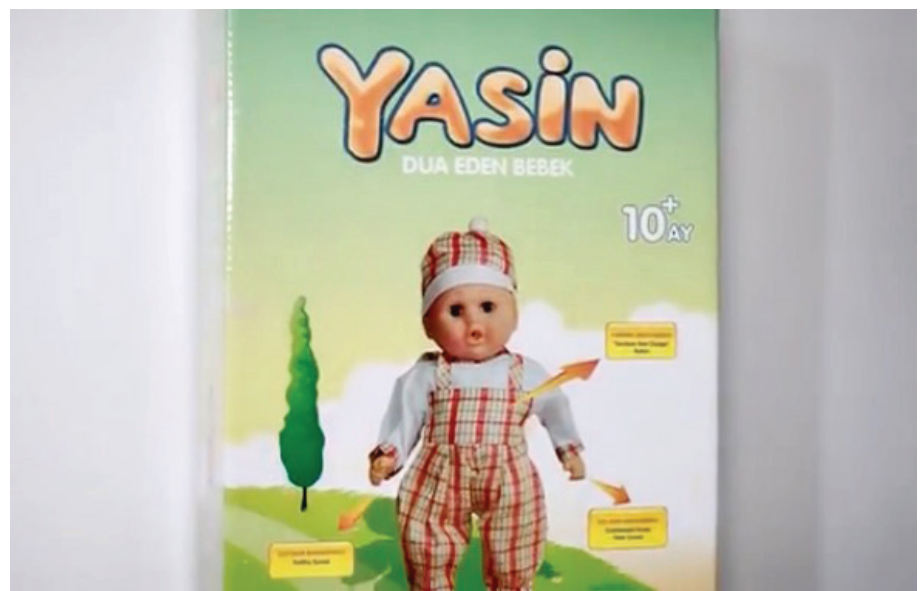

\section{Gösteren: YASIN DUA EDEN BEBEK.}

Gösterilen: Dua eden, bazı Kur'an-1 Kerim surelerini okuyan ve ilahi söyleyen oyuncak bebek, "Yasin" ismi ile sunulmaktadır.

Çözümleme: Reklamda oyuncak bebek, bazı Kur'an-1 Kerim surelerini okuyabilen, dua edebilen, bu sure ve duaların Türkçe ne anlama geldiğini eğlenceli bir şekilde paylaşabilen ve dini konularda son derece bilgili bir bebek olarak tanitılmakta; sesi güzel olan oyuncak bebeğin Türkçe ilahi söylemekte de son derece başarılı olduğ ${ }^{83}$ vurgulanmaktadır. Ürün tanıtım metninde bebeğin sağ eline basıldığında Fatiha Suresi, sol eline basıldığında Sübhaneke Duası ve İhlas Suresi okuduğu, sağ ayağına basıldığında imanın altı şartı ve İslam'ın beş şartını saydığı, sol ayağına basıldığında Türkçe günlük dua ettiği, karnına basıldığında Sordum Sarı Çiçeğe ilahisini okuduğ $u^{84}$ belirtilmektedir. Oyuncak bebeğin ismi, dini bir sembol olan Kur'an-1 Kerim'in Yasin Suresi ile ilişkilendirilmekte ve alıcıları tüketime teşvik etmeye yönelik işlevselleştirilmektedir. Oyuncak bebek, "Yasin" ismi ile piyasada arzulanır ve tercih edilir hale getirilmekte; "Çocuğunuzun oyun oynarken dini bilgilerinin de pekişmesini istiyorsanız Türkçe Dua Eden Yasin Bebek tam size göre! Birbirinden farklı dualar okuyan Yasin Bebek, aynı zamanda ilahiler de söylüyor. Çocuğunuz İslam'ın ve imanın şartlarını da Dua eden Yasin Bebek’ten kolaylıkla öğrenebilecek. Siz de çocuğunuzun dini bilgilerinin artmasını ya da pekişmesini istiyorsanız Türkçe Dua Eden Yasin Bebek ile hemen tanışın!" ${ }^{55}$ mottosu ile tüketici sayısı artırılmaya çalışılmaktadır. Dua eden Yasin

83 https://www.youtube.com/watch?v=iOa7vTMdVDs (Haziran 25, 2020).

$84 \mathrm{https} / / /$ maxbebek.com/birlik-oyuncak-turkce-dua-eden-yasin-bebek-27531 (Haziran 25, 2020).

85 https://maxbebek.com/birlik-oyuncak-turkce-dua-eden-yasin-bebek-27531 (Haziran 25, 2020). 
Bebek, öncelikli olarak gerçek bir gereksinimi karşılamaya yönelik değil; "Yasin" ismi ile piyasada kâr getirme temelinde sergilenmektedir.

\section{Gösterge 10}
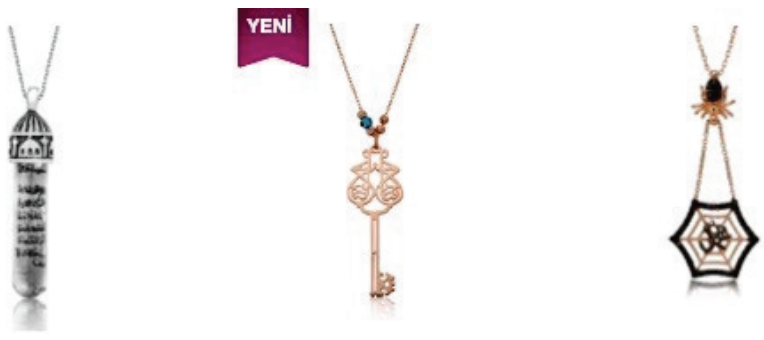

Gümüş Zemzem Sulu ...

Gümüş Ya Fettah Yazı... Gümüş Muhammed Y...

Gösteren: Gümüş Zemzem Sulu Cevşen Kolye, Gümüş Ya Fettah Yazılı Bayan Kolye, Gümüş Muhammed Yazılı Örümcek Ağı Bayan Kolye.

Gösterilen: Değişkenlik mekanizması ile estetize edilip tüketim nesnesine dönüşen dini semboller, pazar için işlevsel şekilde aktarılmaktadır.

Çözümleme: Kültür endüstrisinde sermayenin sürdürülebilirliği sürekli değişimle gerçekleştirilmektedir. Bu nedenle endüstride kültürel içeriklerin ve sembollerin meta nitelikleri sürekli geliştirilmektedir. Tüketim pazarında dini öge ve semboller de değiştirilebildikleri oranda tecimselleşmektedir. ${ }^{86}$ Dini öge ve sembollerin değişim ve kâr getirme potansiyelleri, piyasadaki kalıcılığını belirlemektedir. ${ }^{87}$ Alınıp satılabilen bir metaya dönüşen dini semboller, değişkenlik mekanizması ile her geçen gün farklı şekillerde piyasaya sürülmekte; reklamlar aracılığıyla pazar için işlevsel şekilde aktarılmaya hazır hale getirilerek tüketicilerin beğenisine sunulmaktadır. Değişkenlik mekanizması ile estetize edilip tüketim nesnesi haline getirilen dini semboller, göstergede "İslami Kolye" 88 etiketiyle pazar için işlevsel şekilde aktarılmaya hazır hale getirilmekte ve alıcıların inanç ve değer dünyalarını yansıtan araçlar olarak sunulmaktadır. İçine zemzem suyu konularak pazarlanan cami desenli cevşen kolyenin manevi bir zırh olduğu vurgulanmakta, ${ }^{89}$ kapıları açan anlamına gelen Ya Fettah'ın

86 Birsen Banu Okutan, Türkiye'de Popüler Kültür Din ve Kadın Marjinalizasyondan Entegrasyona (İstanbul: Düşün Yayıncılık, 2013), 96.

87 Okutan, Türkiye'de Popüler Kültür Din ve Kadın, 80.

$88 \mathrm{https}: / /$ www.gumush.com/yeni-gumus-islami-kolye-modelleri-ve-fiyatlari?ps=3 (Nisan 7, 2020).

89 https://www.gumush.com/gumus-cami-desenli-zemzem-sulu-cevsen-kolye (Nisan 7, 2020). 
anahtar kolye şeklinde tecimselleştirildiği Ya Fettah yazılı kolye, "Ya Fettah, Allah'ın en güzel esmalarından bir tanesidir. Hüküm veren, kapıları açıp yardım eden, zafer ve fetih lütfeden ve varlıklara suretler giydiren gibi manalara gelir. Sevdiğiniz kişi ya da kendiniz için yaratıcı modeller sizleri bekliyor." ${ }^{\text {90 }}$ mottosu ile alıcılara iletilmektedir. Muhammed yazılı örümcek ağı kolye, "Bu özel tasarım gümüş kolye modeli, Hz. Muhammed ve Hz. Ebu Bekir'in kâfirlerden kaçarken Sevr mağarasına saklanmalarını, mağara ağzına gelen bir örümceğin kapıyı ağları ile tamamen örterek kâfirlerden korumasını anlatır. Siyah zirkon ve rose 1ş1tısının bir arada olduğu bu şık kolye modeli sizin olduğu kadar sevdiklerinizin de keyifle takacağı dini sembole sahip en güzel hediyelerden biri olacaktır." ${ }^{91}$ mottosu ile pazar için işlevsel şekilde aktarılmaktadır. Reklam aktarımında, ürünlerin özü ve içeriğinden daha çok simgesel bir çağrışımla görüntüleri ön plana çıkarılmaktadır. Görüntüyle öz tanımlanarak özün yerini görüntü almakta ve görüntü popülerleştirilmektedir. Böylece ürünlerin kullanım değerleri, gösterge değerleri ile anlam kazanmaktadır.

\section{Değerlendirme ve Sonuç}

Kültür endüstrisinin yaşam iksiri olan ve piyasa mantığ çerçevesinde işlevsel olarak çalışan reklamlar, dini öge ve sembolleri endüstrinin potasında eritip piyasa ihtiyaçlarına endeksli birer tüketim nesnesine dönüştürmektedir. Reklam sektöründe yüksek kâr marjına sahip yatırım alanlarından biri olarak görülen dini semboller, tüketim stratejileri çerçevesinde metalaştırılmakta; markalaşarak endüstriyel pazara olabildiğince işlevsel bir biçimde uyarlanmaktadır.

Seçilen reklam göstergelerinde dini sembollere atfedilen değerler, araçsallık ve işlevselliktir. Dini semboller, kendi mecralarından koparılıp heterotopik ${ }^{92}$ birlikteliklere zorlanarak tüketilmekte; rekabet ve pazar mantığının işlediği döngüde alınıp satılabilen bir tüketim nesnesine ya da estetik bir biçim kazandırılarak tüketiciyi satın alma faaliyetine yönelten bir arzu ve güdümleme nesnesine dönüşmekte; kimi zaman da reklam retoriği içinde kullanılan bir gimmick olarak işlev görmekte ya da gimmicklerle eklektik bir biçimde işlevselleştirilmektedir. Dini sembollerin alıcıların inanç ve değer dünyalarını yansıtan araçlar olarak sunulması hem müşteri tabanını genişletmekte hem de bireylerin kültür endüstrisi karşısındaki direncini

90 https://www.gumush.com/gumus-ya-fettah-yazili-bayan-kolye (Nisan 7, 2020).

91 https://www.gumush.com/gumus-muhammed-yazili-orumcek-agi-kolye (Nisan 7, 2020).

92 Foucault'nun heterotopia kavramsallaştırması, çok sayıda bölük pörçük olanaklı dünyanın olanaksız bir mekânda birarada var olmasını ya da ortak olarak ölçülemeyeceği halde birbirleriyle yan yana getirilmesini ifade etmektedir. akt. Davıd Harvey, Postmodernliğin Durumu, çev. Sungur Savran (İstanbul: Metis Yayınları, 1997), 64. 
kırarak sistemin egemenliğinin pekişmesine hizmet etmektedir. Böylece endüstri, her geçen gün kendini daha buyurgan bir biçimde hissettirmektedir.

Reklam göstergeleri, dini sembolleri tüketim terminolojisi çerçevesinde bir anlamlandırma sürecinden geçirmekte; piyasa koşullarına uygun olarak yeniden biçimlendirip kendi anlam dünyalarından hızla uzaklaştırmaktadır. Dikkat çeken husus, reklamların dini sembollerin anlamını tamamen silmediği, anlamı özünden uzaklaştırarak yoksullaştırdığı ve sembolleri anlık bir gösterge kaynağı olarak kullandığıdır. Reklamlarda dini sembollerin anlamı ölmemekte; yoksullaşarak yaşamını sürdürmektedir. Dini semboller, reklam göstergelerinde anlam taşıyıcı olmaktan çıkıp nitelikten yoksun göstergelere dönüşmekte; sembollerin anlam taşımasına değil, yalnızca göstermesine izin verilmektedir. İçeriğinden çok görüntüsü sunulan dini semboller, gösterme ve elde tutulma özelliğine sahip bir meta halinde anlam değerinden uzaklaşarak sadece bir gösterge değeri taşımaktadır. Popüler formlarla ilişkilendirilerek kullanılan dini semboller, artık kendi asli özellikleriyle kendi muhatap evrenini bulmakta zorlanmaktadir.

Reklam göstergeleri, bir taraftan dini sembolleri kullanarak bireyleri tüketime yönlendirirken, diğer taraftan bu sembolleri kendi özvarlığından kopararak tüketmekte ve bireylerin dini sembollere yönelik zihin dünyalarındaki anlamsal yapıların dönüşmesine aracılık etmektedir. Reklam göstergelerinde sunulan iletiler sorgulanmadan, analiz edilmeden, diyalektik olmayan bir biçimde kabul edildiği takdirde bilincin yerini uyum sağlama almaktadır. Standartlaşmış kitlesel bir bilinçle bireyler neye uyumlandıklarını farketmeden özvarlığ özyıkıma uğramış dini sembollere zihinsel olarak uyum sağlamaktadır. Reklam göstergelerinin dönüştürerek uyumlaştırıcı etkisi karşısında dini sembollerin kendi özvarlıkları ile ilişki kurabilmek için bilincin kendine dönüp yeniden düşünmesi ve kendini bulması gerekmektedir. Adorno ve Horkheimer'ın tabiriyle "işte her şey o zaman yoluna girecek", ${ }^{93}$ dini semboller de asli özellikleri ile yeniden hayat bulabilecektir.

Hakem Değerlendirmesi: Dış bağımsız.

Çıkar Çatışması: Yazar çıkar çatışması bildirmemiştir.

Finansal Destek: Yazar bu çalışma için finansal destek almadığını beyan etmiştir.

Peer-review: Externally peer-reviewed.

Conflict of Interest: The author has no conflict of interest to declare.

Grant Support: The author declared that this study has received no grant support.

93 Theodor W. Adorno - Max Horkheımer, Teori ve Pratik Üzerine Bir Tartışma, çev. Orhan Kılıç (İstanbul: Metis Yayınları, 2013), 60-61. 


\section{Kaynakça/References}

Adorno, Theodor W. "Kültür Endüstrisini Yeniden Düşünürken”. çev. Bülent O. Doğan. Cogito Adorno: Kitle, Melankoli ve Felsefe 36 (2003): 76-83. İstanbul: Yapı Kredi Yayınları.

Adorno, Theodor W. Edebiyat Yazıları. çev. Sabir Yücesoy - Orhan Koçak. İstanbul: Metis Yayınları, 2004.

Adorno, Theodor W. Kültür Endüstrisi Kültür Yönetimi. çev. Nihat Ülner - Mustafa Tüzel - Elçin Gen. İstanbul: İletişim Yayınları, 6. Baskı, 2011.

Adorno, Theodor W. - Horkheımer, Max. Teori ve Pratik Üzerine Bir Tartışma. çev. Orhan Kılıç. İstanbul: Metis Yayınları, 2013.

Adorno, Theodor W. - Horkheımer, Max. Aydınlanmanın Diyalektiği Felsefi Fragmanlar. çev. Nihat Ülner - Elif Öztarhan Karadoğan. İstanbul: Kabalcı Yayıncılık, 2014.

Barthes, Roland. Göstergebilim Illkeleri. çev. Berke Vardar - Mehmet Rifat. Ankara: Kültür Bakanlığ1 Yayınları, 1979.

Barthes, Roland. Yaşantı. çev. Sema Rifat. İstanbul: Yapı Kredi Yayınları, 1998.

Barthes, Roland. Çağdaş Söylenler. çev. Tahsin Yücel. İstanbul: Metis Yayınları, 4. Basım, 2014.

Barthes, Roland. Bir Deneme Bir Ders: Eiffel Kulesi ve Açıllş Dersi. çev. Mehmet Rifat - Sema Rifat. İstanbul: Yap1 Kredi Yayınları, 2. Bask1, 2015.

Baudrillard, Jean. Nesneler Sistemi. çev. Oğuz Adanır - Aslı Karamollaoğlu. İstanbul: Boğaziçi Üniversitesi Yayınevi, 2010.

Baudrillard, Jean. Simülakrlar ve Simülasyon. çev. Oğuz Adanır. Ankara: Doğu Batı Yayınları, 6. Basım, 2011.

Baudrillard, Jean. Tüketim Toplumu. çev. Hazal Deliceçaylı - Ferda Keskin. İstanbul: Ayrıntı Yayınları, 6. Basim, 2013.

Berger, Arthur Asa. Kültür Eleştirisi Kültürel Kavramlara Girişs. çev. Özgür Emir. İstanbul: Pinhan Yayınc1lık, 2. Bask1, 2014.

Bircan, Ufuk. "Roland Barthes ve Göstergebilim”. Sosyal Bilimler Araştırma Dergisi, 26 (2015): 17-41.

Bocock, Robert. Tüketim. çev. İrem Kutluk. Ankara: Dost Kitabevi Yayınları, 1997.

Bourdieu, Pierre. Televizyon Üzerine. çev. Turhan Ilgaz. İstanbul: Yapı Kredi Yayınları, 1997.

Çamdereli, Mete. "Reklamın R'si ya da Reklam Söylemine Giriş”. İstanbul Üniversitesi İletişim Fakültesi Dergisi 2 (2012): 455-472.

Demirezen, İsmail. Tüketim Toplumu ve Din. İstanbul: Dem Yayınları, 2. Bask1, 2019.

Erdoğan, İrfan - Alemdar, Korkmaz. Popüler Kültür ve İletişim. Ankara: Erk Yayınları, 2. Baskı, 2005.

Guiraud, Pierre. Göstergebilim. çev. Mehmet Yalçın. Ankara: İmge Kitabevi, 2. Baskı, 1994.

Harvey, Davıd. Postmodernliğin Durumu. çev. Sungur Savran. İstanbul: Metis Yayınları, 1997.

Horkheımer, Max. Akıl Tutulması. çev. Orhan Koçak. İstanbul: Metis Yayınları, 9. Basım, 2013.

Kellner, Douglas. "Kültürel Marksizm ve Kültürel Çalışmalar”. çev. Fatih Tezcan. ETHOS: Felsefe ve Toplumsal Bilimlerde Diyaloglar 9(2) (2016): 132-151.

Marcuse, Herbert. Tek Boyutlu İnsan İleri İşleyim Toplumunun İdeolojisi Üzerine İncelemeler. çev. Aziz Yardımlı. İstanbul: İdea Yayınları, 2. Baskı, 1990.

Mattelart, Armand. Reklamcılık. çev. Fatoş Ersoy. İstanbul: İletişim Yayınları, 1991. 
Okutan, Birsen Banu. Türkiye'de Popüler Kültür Din ve Kadın Marjinalizasyondan Entegrasyona. İstanbul: Düşün Yayıncılık, 2013.

Okutan, Birsen Banu. Din Sosyolojisi ve Göstergebilim. İstanbul: Rağbet Yayınları, 2018.

Ritzer, George. Toplumun McDonaldlaştırılması Çă̆daş Toplum Yaşamının Değişen Karakteri Üzerine Bir İnceleme. çev. Şen Süer Kaya. İstanbul: Ayrıntı Yayınları, 2. Basım, 2011.

Ritzer, George. Modern Sosyoloji Kuramları. çev. Himmet Hülür. Ankara: De Ki Basım Yayım, 2012.

Slater, Phı1. Frankfurt Okulu. çev. Ahmet Özden. İstanbul: Kabalc1 Yayınevi, 1998.

Slattery, Martin. Sosyolojide Temel Fikirler. çev. Ümit Tatlıcan - Gülhan Demiriz. İstanbul: Sentez Yayıncılık, 8. Basım, 2015.

\section{İnternet Kaynakları}

Gösterge 1: Nisan 3, 2020.

https://www.youtube.com/watch?v=KOq8R5OL1U8

Gösterge 2: Nisan 3, 2020.

https://www.youtube.com/watch?v=lbYpiG4Zow4

Gösterge 3: Nisan 4, 2020.

https://www.ipekevi.com/world-art-koleksiyonu

https://www.ipekevi.com/kaplumbaga-terbiyecisi-saten-ipek-esarp-0111301005090

Gösterge 4: Mart 28, 2020.

https://www.vakko.com/esarp/90x90-twill-p868139096165/

Gösterge 5: Mart 28, 2020.

https://banaduaoku.com/dualar/corona-virusunden-koruma-duasi/

Gösterge 6: Nisan 26, 2020.

https://www.gittigidiyor.com/kampanya/ramazan-paketi

Gösterge 7: Nisan 26, 2020.

https://www.n11.com/kampanyalar/ramazan-kampanyasi

Gösterge 8: Ekim 23, 2020.

https://www.ciceksepeti.com/kabe-ortusu-esansi--orjinal-kabe-ortu-kokusu--5125-kc483467

Gösterge 9: Haziran 25, 2020.

https://www.youtube.com/watch?v=iOa7vTMdVDs

Gösterge 10: Nisan 7, 2020.

https://www.gumush.com/gumus-cami-desenli-zemzem-sulu-cevsen-kolye

https://www.gumush.com/gumus-ya-fettah-yazili-bayan-kolye

https://www.gumush.com/gumus-muhammed-yazili-orumcek-agi-kolye 